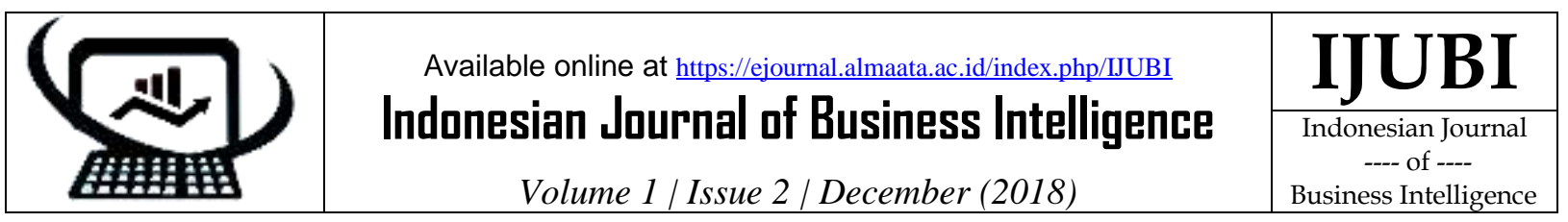

\title{
MEMBANGUN MEDIA PEMBELAJARAN 7 KEAJAIBAN DUNIA BERBASIS AUGMENTED REALITY PADA MATA PELAJARAN ILMU PENGETAHUAN SOSIAL KELAS VI
}

Akbar Permana Putra ${ }^{1}$, Tri Widodo ${ }^{2}$, Tri Rochmadi ${ }^{3}$

12Program Studi Pendidikan Teknologi Informasi, Fakultas Humaniora, Pendidikan dan Pariwisata, Universitas Teknologi Yogyakarta

3Program Studi Sistem Informasi, Fakultas Komputer, Universitas Alma Ata

19akbarpermana39@yahoo.co.id, ${ }^{2}$ triwidodo@uty.ac.id, ${ }^{3}$ trirochmadi@almaata.ac.id

${ }^{12} \mathrm{Jl}$. Siliwangi Jombor, Sleman, Yogyakarta, ${ }^{3} \mathrm{Jl}$. Brawijaya No. 99 Yogayakarta

\section{Keywords:}

learning media, wonders of the world, augmented reality, android.

\section{Kata Kunci:}

media pembelajaran keajaiban dunia, augmented reality, android.

\section{Abstract}

Educational Equity in Indonesia is categorized low, it is approved by decreased amount of facilities used in learning process. There are finded in only particular sectors like city, then in village and minorities have not been got the same right. The using of learning media is so helpful in delivering the material among to the students and can be used as dynamic teaching material so it can help in catching and understanding the material. Augmented reality is one of technological development that can be used in making learning media in android operation system with using marker as object reader such as seven wonders of the world. The using of augmented reality makes the object more factual so it can increase students's motivation in learning. The method used in making this media is Systems Development Life Cycle method followed as 1) Analysis, 2) Design, 3) Testing, 4) Implementation and 5) Maintenance. Testing in making learning media application seven wonders of the world is applied with using black box testing and media expert, material expert and users's testing. The testing result presents this media can help teaching learning process with percentage average is $99.09 \%$ got from media expert's testing in 100\%, material expert' testing in 100\%, and user's testing in $97,27 \%$. It means this learning media is so practiced.

\section{Abstrak}

Pemerataan pendidikan di Indonesia dirasa masih kurang, dibuktikan dengan kurangnya sarana prasarana yang digunakan dalam proses pembelajaran. Sarana dan prasarana hanya terdapat pada sektor-sektor tertentu saja seperti perkotaan, sedangkan pada pedesaan dan masyarakat yang tergolong minoritas belum mendapatkan hak yang sama. Penggunaan media pembelajaran dirasa sangat membantu dalam penyampaian materi kepada siswa dan dapat digunakan sebagai bahan ajar yang dinamis sehingga dapat membantu dalam penyerapan dan pemahaman materi yang disampaikan karena kurangnya sarana prasarana yang disediakan. Augmented Reality adalah salah satu perkembangan teknologi yang dapat diterapkan dalam pembuatan media pembelajaran dalam sistem operasi android dengan memanfaatkan marker sebagai pembaca obyek 3 dimensi berupa 7 keajaiban dunia. Penggunaan Augmented Reality dapat menjadikan obyek lebih terlihat nyata sehingga dapat meningkatkan motivasi siswa dalam belajar. Metode yang digunakan dalam pembuatan media ini menggunakan metode Systems Development Life Cycle yang terdiri dari: 1) Analisis, 2)Desain, 3)Testing, 4)Implementasi dan 5)Pemeliharaan. Pengujian pada pembuatan aplikasi media pembelajaran 7 keajaiban dunia dilakukan dengan menggunakan black box testing dan pengujian kepada ahli media, ahli materi dan pengguna. Hasil pengujian media pembelajaran 7 keajaiban dunia menunjukkan bahwa media 
yang dikembangkan penulis dapat membantu dalam proses belajar mengajar di sekolah dengan rata-rata presentase sebanyak $90.37 \%$ yang didapat dari hasil uji ahli media $86,36 \%$, hasil uji ahli materi $87,5 \%$, dan hasil uji pengguna $97,27 \%$. Artinya media pembelajaran ini dinilai sangat praktis.

\section{Pendahuluan}

Negara Kesatuan Republik Indonesia (NKRI) adalah salah satu Negara yang memiliki luas yang besar di dunia. Menurut Badan Pusat Statistik (BPS) [1] pada tahun 2017 Indonesia memiliki jumlah penduduk mencapai 261 juta jiwa dan terus mengalami peningkatan. Menurut UU No.20 (2003) [2] menyebutkan bahwa pada usia 621 tahun masyarakat Indonesia wajib menempuh pendidikan hingga menengah atas. Namun faktanya sebanyak 117 juta (umur 15+) warga Indonesia masih buta huruf. Hal tersebut diikuti dengan banyaknya anak-anak Indonesia yang putus maupun tidak pernah sekolah sebanyak 75 juta penduduk (umur 7-24 tahun). Pemerataan pendidikan di Indonesia dirasa masih kurang, dibuktikan dengan kurangnya sarana prasarana yang digunakan dalam proses pembelajaran. Sarana dan prasarana hanya terdapat pada sektor-sektor tertentu saja seperti perkotaan, sedangkan pada pedesaan dan masyarakat yang tergolong minoritas belum mendapatkan hak yang sama, seperti anak yatim piatu dan disabilitas. Berdasarkan latar belakang tersebut maka peneliti mengambil proyek tugas akhir dengan judul Membangun Aplikasi Media Pembelajaran 7 Keajaiban Dunia Bebasis Augmented Reality yang dapat digunakan oleh berbagai pihak seperti siswa sekolah dasar, anak yatim piatu hingga penyandang disabilitas dalam mempelajari materi untuk membantu upaya pemerintah dalam memenuhi hak masyarakat Indonesia dalam menempuh pendidikan.

\section{Landasan Teori}

Penelitian oleh Aprillia, A.R. [3] dengan judul Aplikasi Informasi Mengenai 7 Keajaiban Dunia Berbasis Augmented Reality Dengan Metode Marker Based Tracking. Penelitian tersebut membahas bagaimana menciptakan sebuah media pembelajaran untuk memberikan informasi mengenai 7 keajaiban dunia agar proses belajar tidak menjadi monoton dengan memanfaatkan teknologi Augmented Reality.
Jenis media pembelajaran yang telah dikembangkan yaitu dengan metode marker based tracking, dimana sebuah gambar dijadikan marker untuk menampilkan objek tiga dimensi ketika aplikasi dijalankan didalam smartphone, kamera pada smartphone diarahkan pada gambar tersebut, perancangan dan pembuatan aplikasi augmented reality menggunakan software Unity dan Vuforia. Berdasarkan kajian pustaka tersebut, peneliti ingin mengembangkan media pembelajaran 7 keajaiban dunia berbasis Augmented Reality yang dilengkapi dengan fiturfitur tertentu guna melengkapi kekurangan dari penelitian yang sudah pernah dilakukan sebelumnya, diantaranya ialah dalam kelengkapan informasi terkait 7 keajaiban dunia, terdapat audio/suara, terdapat kuis/latihan soal pada aplikasi, terdapat keterangan tentang 7 keajaiban dunia dan mendesain tampilan semenarik mungkin.

\section{Metode}

Menurut Agitya, L. [4], SDLC (Systems Development Life Cycle) dalam rekayasa sistem dan rekayasa perangkat lunak adalah proses pembuat dan pengubahan sistem serta model dengan metodologi yang diguanakan untuk mengembangkan sistem tersebut. Konsep utamanya merujuk pada sistem komputer atau informasi. Dalam rekayasa perangkat lunak konsep SDLC (Systems Development Life Cycle) mendasari berbagai jenis metodologi pengembangan perangkat lunak.

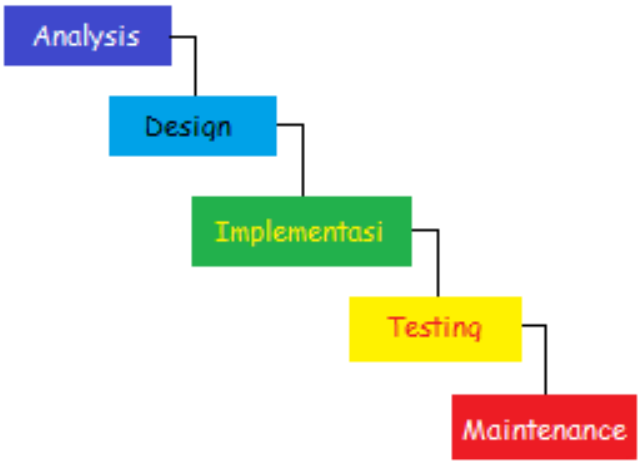

Gambar 1. Metode SDLC 
Metodologi-metodologi ini membentuk suatu kerangka kerja untuk perancangan rekayasa perangkat lunak. Metode SDLC seringkali dinamakan sebagai proses pemecahan masalah yang terbagi ke dalam 5 tahap yaitu tahapan analisa sistem, tahapan desain, tahapan implementasi, tahapan testing, dan pemeliharaan. Pada setiap tahapan dianalogikan dari bawah lingkran hingga atas lingkaran, artinya sebuah proses bisa dilanjutkan setelah satu tahap awal selesai dengan sempuran. Penjelasan setiap tahap dapat diringkas sebagai berikut:

\section{Tahapan Analisis}

Pada tahapan ini berlangsung proses pengumpulan kebutuhan secara lengkap untuk dianalisis dan didefinisikan kebutuhan apa saja yang harus dipenuhi oleh program yang akan dibuat. Pada tahapan ini penulis melakukan beberapa analisis, diantaranya analisis objek yang akan ditampilkan melalui studi pustaka terkait 7 keajaiban dunia. Selain itu, penulis menganalisis kebutuhan desain pada media yang akan dikembangkan dan kebutuhan dalam pengembangan media pembelajaran.

\section{Tahapan Desain}

Proses ini merupakan gambaran rancangan desain objek 7 keajaiban dunia, desain marker yang akan dibuat dan interface yang akan dibuat. Tahap ini biasanya menggunakan storyboard untuk menggambarkan deskripsi tiap objek, dengan mencantumkan semua objek multimedia dan tautan ke scene lain dan bagan alir (flowchart) untuk menggambarkan aliran dari jalannya program/aplikasi.

\section{Tahapan Pengembang}

Proses penerjemahan desain kedalam bentuk bahasa mesin yang akan dilakukan secara mekanis. Pada tahapan ini penulis mulai mengembangkan media pembelajaran menggunakan beberapa tool (alat) berupa software untuk mengembangkan sistem, hardware spesifikasi yang diperlukan.

\section{Tahapan Pengujian}

Proses ini dikerjakan setelah kode dirancang dan difokuskan pada setiap fungsi yang di buat agar mengetahui kesalahan yang ada pada aplikasi agar kedepannya dapat diperbaiki. Tahapan pengujian meliputi beberapa langkah, diantaranya pengujian blackbox, pengujian ahli media, ahli materi dan pengguna dengan menggunakan kisi-kisi instrument yang telah penulis tentukan. Teknik pengumpulan data dalam pengembangan Media Pembelajaran 7 Keajaiban Dunia Berbasis Augmented Reality ini menggunakan metode kuesioner/angket. Penyusun menggunakan kuesioner dan responden tinggal memilih beberapa alternatif jawaban yang tersedia. Penyusun menggunakan kuesioner dengan skala Guttman. Penelitian menggunakan skala guttman dilakukan bila ingin mendapatkan jawaban yang tegas (konsisten) terhadap suatu permasalahan yang ditanyakan. Kusesioner/Angket diberikan kepada beberapa pihak, yaitu Ahli Media, Ahli Materi dan Pengguna. Berikut ini diberikan kisi-kisi instrumen kepada masing-masing responden. Kisi-kisi instrument untuk Ahli Media dapat ditinjau dari beberapa aspek, yaitu : (1) Pengoperasian Program, (2) Desain layar, (3) Kemanfaatan, (4) Navigasi, (5) Konsistensi. Metode pengujian yang digunakan dalam penelitian ini menggunakan beberapa pengujian, diantaranya :

\section{a. Pengujian Black Box}

Pengujian Black Box berfokus pada persyaratan fungsional perangkat lunak. Metode pengujian black box ini menggunakan pengujian alpha. Terfokus pada apakah ini program memenuhi kebutuhan yang disebutkan dalam spesifikasi. Pada Black Box Testing, cara pengujian hanya dilakukan dengan menjalankan atau mengeksekusi unit atau modul, kemudian diamati apakah hasil dari unit itu sesuai dengan proses bisnis yang diinginkan [5].

b. Pengujian ahli media

Pengujian ahli media dilakukan untuk mengetahui kualitas dari media yangdikembangkan, apakah sudah layak atau belum untuk didistribusikan ke siswa maupun masyarakat umum.

\section{c. Pengujian ahli materi}

Pengujian ahli materi dilakukan untuk mengetahui apakah materi yang disajikan pada aplikasi sudah sesuai dengan kompetensi dasar/silabus dari mata pelajaran ilmu pengetahuan sosial. 


\section{d. Pengujian pengguna}

Pengujian pengguna dilakukan untuk mengetahui apakah aplikasi sudah dapat dioperasikan dengan baik dan mudah digunakan oleh pengguna.

\section{Hasil dan Pembahasan}

Cara kerja sistem dalam aplikasi ini dijelaskan dalam tiap-tiap tampilan aplikasi. Langkahlangkah dari proses cara kerja sistem adalah urutan dari kegiatan awal sampai kegiatan akhir yang harus dilakukan dalam mewujudkan sistem yang dirancang. Sistem ini dibuat secara komputerisasi yang menggunakan bahasa pemrograman C\# (Sharp), Unity dan Vuforia sdk sebagai database. Kita harus hadapkan marker ke depan webcam. Setelah itu, akan melewati proses pendeteksian dan pengkalkulasian gambar, seperti terlihat pada gambar 1 .

a. Webcam akan mendeteksi secara keseluruhan marker. Fungsi webcam disini seperti sebuah cermin, menampilkan objek yang kita buat secara terbalik. Proses ini disebut dengan Get Webcam Image.

b. Proses labeling, dalam proses ini pola dari marker yang kita buat akan ditemukan. Dari pola kotak tersebut maka akan dilakukan proses pencarian posisi 3D pada marker.

c. Proses identifikasi marker, proses ini akan melakukan pencocokan serta perhitungan marker yang ada dengan marker yang dideteksi melalui kamera.

d. Setelah marker sesuai dengan marker yang ada, maka objek akan dirender serta ditampilkan kedunia virtual.

e. Jika marker yang dideteksi tidak sesuai, maka akan terus melakukan identifikasi pada marker sampai ditemukan sebuah objek virtual.

f. Proses terakhir adalah memilih marker dan objek yang sesuai lalu merender objek serta mengeluarkan objek tersebut diatas marker.

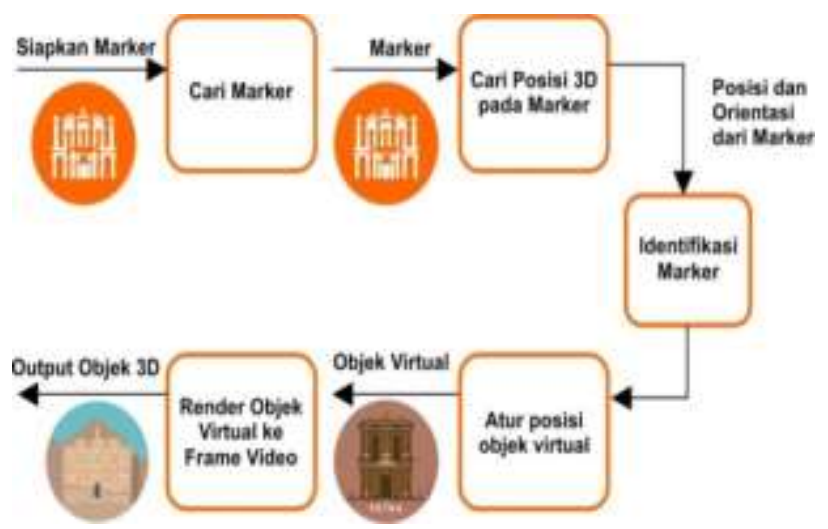

Gambar 2. Pembacaan Marker Menjadi Objek

\section{Tampilan Utama}

Tampilan awal dari aplikasi Augmented Reality 7 Keajaiban Dunia ini muncul setelah proses loading selesai. Pada tampilan utama ini tersedia menu petunjuk, tentang, silabus, menu AR dan tombol keluar. Tampilan utama dari aplikasi Augmented Reality 7 keajaiban dunia ini dapat dilihat seperti pada gambar 3 .

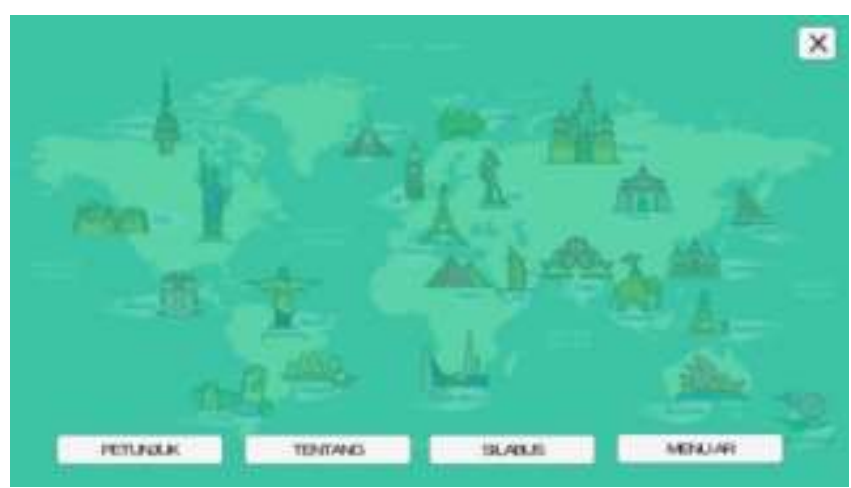

Gambar 3. Tampilan Utama

\section{Tampilan Petunjuk}

Tampilan petunjuk dari aplikasi Augmented Reality 7 Keajaiban Dunia ini muncul setelah tombol petunjuk diklik. Pada tampilan petunjuk ini berisi tentang petunjuk penggunaan aplikasi. Tampilan petunjuk dari aplikasi Augmented Reality 7 keajaiban dunia ini dapat dilihat seperti pada gambar 4. 


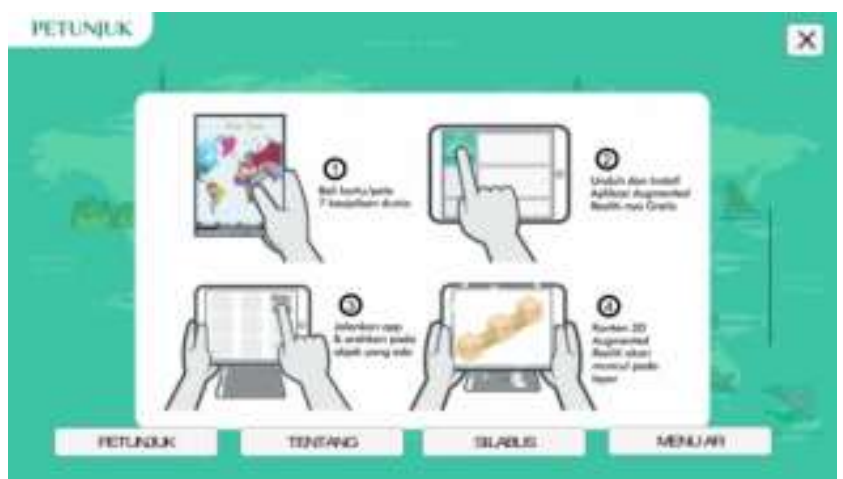

Gambar 4. Tampilan Petunjuk

\section{Gambar Marker}

Gambar marker digunakan untuk media agar augmented reality bisa ditampilkan. Tampilan/gambar marker dari aplikasi ini dapat dilihat seperti pada gambar 5 .

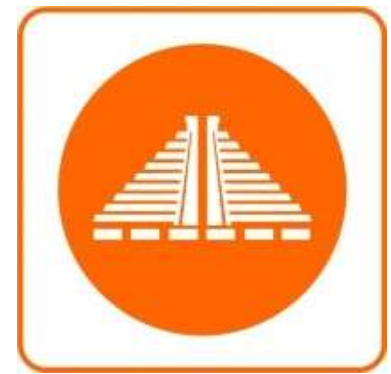

\section{Gambar 5. Gambar Marker}

\section{Tampilan Hasil Pembacaan Marker}

Tampilan hasil AR setelah diarahkan ke marker. Tampilan 1 dari aplikasi ini dapat dilihat seperti pada gambar 6 .

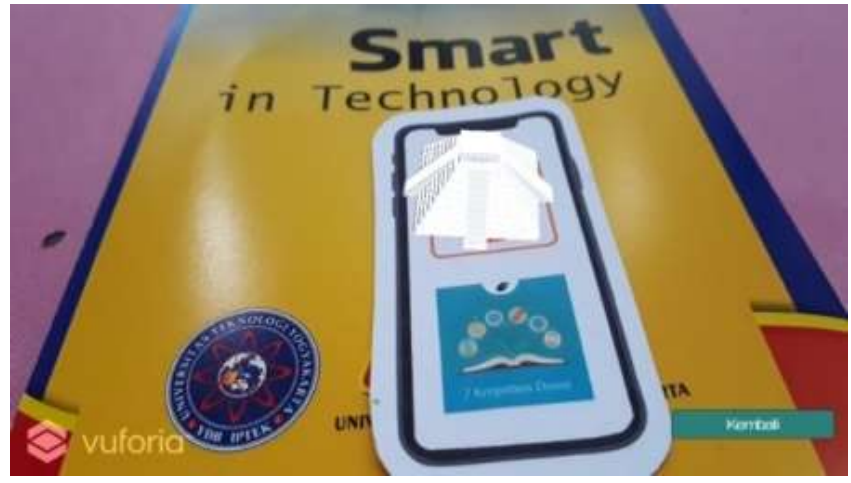

Gambar 6. Tampilan Hasil Pembacaan Marker

\section{Hasil Pengujian}

Pengujian black box digunakan untuk melakukan pengujian terhadap sistem guna mengetahui apakah software yang dibuat sesuai dengan yang diharapkan atau tidak. Tujuan pengujian black box adalah untuk menemukan kesalahan fungsi eksekusi melalui data uji dan memeriksa fungsional dari software. Hasil pengujian seperti terlihat pada tabel 1.
Tabel 1. Hasil Pengujian Blax Box

\begin{tabular}{|c|c|c|}
\hline Pengujian & Keterangan & Kesimpulan \\
\hline Splash Screen & $\begin{array}{l}\text { menampilkan splash } \\
\text { screen }\end{array}$ & berhasil \\
\hline Main Menu & $\begin{array}{l}\text { menampilkan button } \\
\text { play dan exit }\end{array}$ & berhasil \\
\hline Button About & $\begin{array}{l}\text { menampilkan pop up } \\
\text { tentang }\end{array}$ & berhasil \\
\hline Button Exit & $\begin{array}{l}\text { menghentikan } \\
\text { aplikasi }\end{array}$ & berhasil \\
\hline Back Button & $\begin{array}{l}\text { menampilkan menu } \\
\text { sebelumnya }\end{array}$ & berhasil \\
\hline $\begin{array}{l}\text { Play Button Main } \\
\text { Menu }\end{array}$ & $\begin{array}{l}\text { menampilkan } \mathrm{AR} \\
\text { video }\end{array}$ & berhasil \\
\hline $\begin{array}{ll}\text { Button } & \text { Start } \\
\text { Recoder } & \end{array}$ & $\begin{array}{l}\text { menampilkan button } \\
\text { play/stop }\end{array}$ & berhasil \\
\hline
\end{tabular}

Berdasarkan validasi yang dilakukan pada 21 Januari 2019 kepada ahli materi, pengguna dan kepada ahli media, didapatkan hasil pada tabel 2 dan 3.

Tabel 2. Hasil Validasi Ahli Media

\begin{tabular}{|c|c|c|c|}
\hline \multirow[t]{2}{*}{ Aspek } & \multirow[t]{2}{*}{ Pertanyaan } & \multicolumn{2}{|c|}{ Jawaban } \\
\hline & & Ya & No \\
\hline \multirow[t]{4}{*}{ Pengoperasian } & Program mudah digunakan? & $\checkmark$ & \\
\hline & $\begin{array}{l}\text { Ada petunjuk penggunaan } \\
\text { program? }\end{array}$ & $\checkmark$ & \\
\hline & Bersifat interaktif? & $\checkmark$ & \\
\hline & Program mudah diinstal? & $\checkmark$ & \\
\hline \multirow[t]{8}{*}{ Desain } & Tulisan mudah dibaca? & $\checkmark$ & \\
\hline & Jenis tulisan sudah tepat? & $\checkmark$ & \\
\hline & Komposisi warna tepat? & & $\checkmark$ \\
\hline & $\begin{array}{l}\text { Komposisi letak tulisan } \\
\text { dengan background tepat? }\end{array}$ & $\checkmark$ & \\
\hline & $\begin{array}{l}\text { Komposisi gambar terhadap } \\
\text { background tepat? }\end{array}$ & $\checkmark$ & \\
\hline & $\begin{array}{l}\text { Gambar yang disajikan } \\
\text { sesuai materi? }\end{array}$ & $\checkmark$ & \\
\hline & $\begin{array}{l}\text { Penggunanan audio sudah } \\
\text { jelas? }\end{array}$ & $\checkmark$ & \\
\hline & Desain program menarik? & & $\checkmark$ \\
\hline \multirow[t]{2}{*}{ Manfaat } & $\begin{array}{l}\text { Mempermudah } \\
\text { penyamapaian materi? }\end{array}$ & $\checkmark$ & \\
\hline & $\begin{array}{l}\text { Program dapat digunakan } \\
\text { secara mandiri? }\end{array}$ & $\checkmark$ & \\
\hline \multirow[t]{3}{*}{ Navigasi } & Fungsi navigasi sudah tepat? & $\checkmark$ & \\
\hline & Navigasi mudah digunakan? & $\checkmark$ & \\
\hline & Icon sesuai kegunaan? & $\checkmark$ & \\
\hline \multirow[t]{5}{*}{ Konsistensi } & Ukuran tulisan konsisten? & $\checkmark$ & \\
\hline & Tata letak desain konsisten? & $\checkmark$ & \\
\hline & Program tampilan konsisten? & $\checkmark$ & \\
\hline & Desain tampilan seimbang? & $\checkmark$ & \\
\hline & Kesatuan tampilan sesuai? & & $\checkmark$ \\
\hline
\end{tabular}


Tabel 3. Hasil Validasi Ahli Materi

\begin{tabular}{|c|c|c|c|}
\hline \multirow[t]{2}{*}{ Aspek } & \multirow[t]{2}{*}{ Pertanyaan } & \multicolumn{2}{|c|}{ Jawaban } \\
\hline & & Ya & No \\
\hline Kualitas & Materi sesuai KD/Silabus? & $\checkmark$ & \\
\hline \multirow[t]{3}{*}{ Materi } & Materi sudah benar? & $\checkmark$ & \\
\hline & $\begin{array}{l}\text { Penyajian materi sudah } \\
\text { runtut sesuai KD? }\end{array}$ & $\checkmark$ & \\
\hline & $\begin{array}{l}\text { Materi sudah lengkap sesuai } \\
\text { KD? }\end{array}$ & & $\checkmark$ \\
\hline \multirow{5}{*}{$\begin{array}{l}\text { Kemanfaatan } \\
\text { Materi }\end{array}$} & Membantu guru & $\checkmark$ & \\
\hline & menyampaikan materi? & & \\
\hline & $\begin{array}{l}\text { Membantu peserta didik } \\
\text { memahami materi? }\end{array}$ & $\checkmark$ & \\
\hline & $\begin{array}{l}\text { Membantu peserta didik } \\
\text { memahami letak } 7 \text { keajaiban } \\
\text { dunia? }\end{array}$ & $\checkmark$ & \\
\hline & $\begin{array}{l}\text { Membantu peserta didik } \\
\text { mengetahui } 7 \text { keajaiban } \\
\text { dunia? }\end{array}$ & $\checkmark$ & \\
\hline
\end{tabular}

Setelah dilakukan pengambilan data dari ahli media, ahli media dan pengguna, kemudian dilakukan perhitungan hasil akhir dari skor angket dan diambil nilai rata-rata dari penjumlahan tersebut, seperti pada table 4 .

Tabel 4. Hasil Analisa Deskriptif Uji Kelayakan Secara Keseluruhan

\begin{tabular}{lcc}
\hline \multicolumn{1}{c}{ Responden } & Presentase & Kategori \\
\hline Hasil Uji Ahli Media & 86,36 & Sangat Praktis \\
Hasil Uji Ahli Materi & 87,50 & Sangat Praktis \\
Hasil Uji Pengguna & 97,27 & Sangat Praktis \\
Rata-Rata & 90,37 & Sangat Praktis \\
\hline
\end{tabular}

Hasil analisa deskriptif uji kelayakan secara keseluruhan menunjukan bahwa Media Pembelajaran 7 Keajaiban Dunia Berbasis Augmented Reality Pada Mata Pelajaran Ilmu Pengetahuan Sosial dinilai sangat praktis. Media ini dapat digunakan sebagai bahan ajar guru dalam penyampaian materi 7 keajaiban dunia.

\section{Kesimpulan dan Saran}

Kesimpulannya adalah deskripsi dari keseluruhan proses dan hasil penelitian. Ditulis dalam bahasa yang lebih umum dan menjawab masalah penelitian.

Saran diajukan tentang daya tarik peneliti kepada pembaca lain untuk melakukan penyelidikan lebih lanjut. Di sisi lain, perlu memasukkan rekomendasi yang relevan dari temuan penelitian.

\section{Referensi}

[1] Badan Pusat Statistik (2017), Jumlah Penduduk Indonesia, website:https://www.bps.go.id/statictable/ 2014/09/05/1533/persentase-pendudukusia-7-24-tahun-menurut-jenis-kelaminkelompok-umur-sekolah-dan-partisipasisekolah-1-2002-2016 .html, Diakses pada 23 Februari 2018

[2] Undang-Undang No.20 (2003), Sisdiknas Pasal 1 Ayat 20.

[3] Aprillia, A. R. (2016), Aplikasi Informasi Mengenai 7 Keajaiban Dunia Berbasis Augmented Reality Dengan Metode Marker Based Tracking, Presentasi Karya Ilmiah, Universitas Gunadarma, Depok.

[4] Agitya, L. (2013), "Eksplorasi Metodologi SDLC". Sistem Informasi, Tugas Akhir, S.Kom, UNIKOM Bandung.

[5] Rosa dan Salahuddin M, (2011), Modul Pembelajaran Rekayasa Perangkat Lunak (Terstruktur dan Berorientasi Objek), Modula: Bandung. 